\title{
Transient Analysis of a Modular Multilevel Converter With Coupled Arm Inductors
}

\author{
Bogdan Džonlaga*, Davi Rabelo Joca*†, Loïc Quéval* and Jean-Claude Vannier* \\ ${ }^{*}$ GeePs, UMR CNRS 8507, CentraleSupélec, Univ. Paris-Sud, Univ. Paris-Saclay, Sorbonne Univ., UPMC Univ. Paris 06, \\ 3 \& 11 rue Joliot-Curie, Plateau de Moulon, 91192 Gif-sur-Yvette cedex, France \\ Email: bogdan.dzonlaga@geeps.centralesupelec.fr \\ ${ }^{\dagger}$ Department of Electrical Engineering, Federal University of Ceará, Fortaleza, Brazil \\ Email: davijoca@dee.ufc.br
}

\begin{abstract}
The influence of the coupling of the arm inductors of a modular multilevel converter has been investigated through transient simulations. In particular, positive, negative and zero coupling coefficient were considered for both steady-state and transient operating conditions. The effect of the coupling on the transient response, the capacitor voltage ripple, the circulating current, the DC short-circuit current and the switch power losses has been closely examined. The possibility to reduce either the circulating current or the DC short-circuit current has been demonstrated, opening the door to improved performances of modular multilevel converter with only minor modifications.
\end{abstract}

\section{INTRODUCTION}

The Modular Multilevel Converter (MMC) is a promising solution when it comes to the constitution of High Voltage Direct Current (HVDC) grids because of its modularity, low frequency operation and good harmonic performance [1][3]. One of the problems nowadays associated with MMC and HVDC grids is the DC fault. Given that the half-bridge MMC does not provide protection against DC faults [4], DC breakers have been proposed [5], [6] but they are not yet commercially available. Also, the full-bridge MMC has been proposed but it is more expensive due to a larger number of components and higher power losses [3], [4], [7], [8]. Another problem with MMC is the circulating current which impacts the power losses [3]. Circulating Current Suppression Controllers (CCSC) have been proposed as a solution [3]. The influence of the inductance on the circulating current amplitude was proposed in [9] testifying that the increased inductance can diminish the circulating current amplitude. On the other hand, big inductance would result in bigger cost and size of the inductor. For this, coupling of the arm inductors has been proposed in [10]. The coupling reduces size, weight and the cost of the magnetic components in the comparison to the non-coupled inductors of a traditional MMC [10].

The coupling of the arm inductors of an MMC has been studied in [10]-[12]. Shi et al. presented the design of the inductors and the overall operation of the MMC with different types of modulation. Kucka et al. considered an MMC with all the arm inductors placed on a single magnetic core. Finally, Yuan et al. proposed an improved method of capacitor voltage sorting across the phases of the MMC with coupled arms inductors. However, none of the above considered the influence of the coupled arm inductors on the DC short-circuit current.
Furthermore, the coupled inductors also affect the module capacitor voltage ripple and the switch losses.

This article deals with the coupling of the arm inductors in each phase of the half-bridge MMC. The mathematical model and coupling coefficient definition are elaborated in Section II, along with the capacitor and inductor design. Section III presents the simulation results for positive, negative and zero coupling coefficient. It focuses on the impact of the coupling of the arm inductors on the capacitor voltage ripple, the circulating current, the DC short-circuit current and the switch power losses. This section demonstrates the reduction of the DC short-circuit current and the circulating current as well.

\section{Modeling of The MMC With COUPLED ARM INDUCTORS}

\section{A. Mathematical model}

The considered MMC is a 3-phase AC/DC converter (Fig. 1). Each phase consists of 2 arms. Each arm consists of 5 modules connected in series with an inductor. Each module consists of a half-bridge and a capacitor (Fig. 2). The subscripts "a", "b" and "c" denote the phases whereas the subscripts "u" and "l" denote to the upper and lower arms.

Omitting the phase subscript, the equations for one phase are [12],

$$
\begin{gathered}
\frac{v_{d c}}{2}=v_{u}+R i_{u}+L \frac{d i_{u}}{d t}+M \frac{d i_{l}}{d t}+v_{s} \\
\frac{v_{d c}}{2}=v_{l}+R i_{l}+L \frac{d i_{l}}{d t}+M \frac{d i_{u}}{d t}-v_{s}
\end{gathered}
$$

where $v_{u}$ and $v_{l}$ are the voltages across upper and lower arm respectively, $v_{d c}$ is the DC side voltage, $R$ is the resistance of the arm inductor, $L$ is the arm inductance, $M$ is the mutual inductance between the two inductors in the same phase, and $i_{u}$ and $i_{l}$ are the upper and lower arm currents, respectively. The AC grid current $i_{s}$ and the differential current $i_{d i f f}$ are defined as,

$$
\begin{gathered}
i_{s}=i_{u}-i_{l} \\
i_{d i f f}=\frac{i_{u}+i_{l}}{2}
\end{gathered}
$$




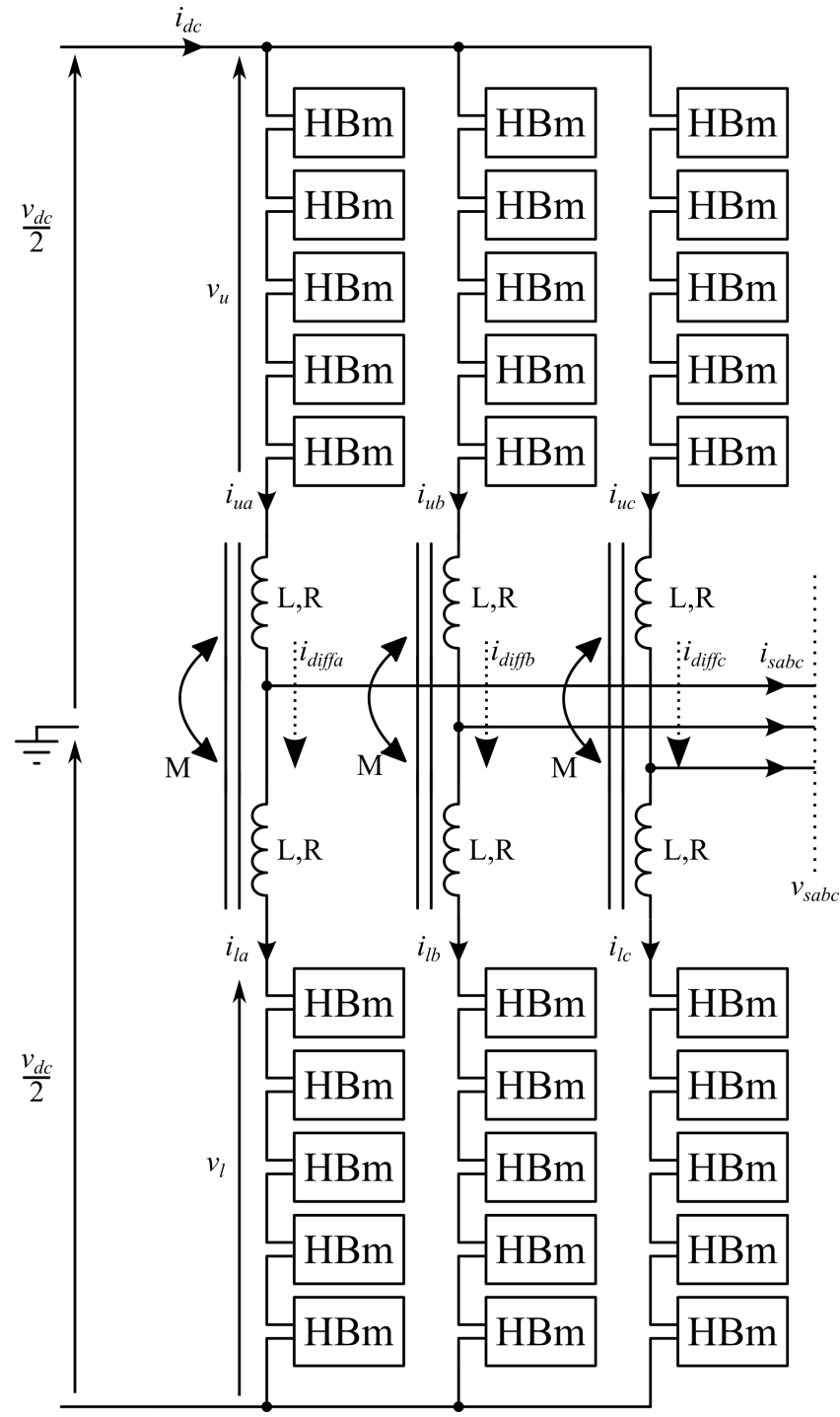

Fig. 1. 3-phase MMC with coupled arm inductors

It is assumed that the triphasic system is symmetric and that the DC grid current $i_{d c}$ divides equally across the three phases of the converter. It is possible to rewrite the differential, upper and lower arm currents as [3],

$$
\begin{gathered}
i_{d i f f}=\frac{i_{d c}}{3}+i_{c} \\
i_{u}=\frac{i_{d c}}{3}+\frac{i_{s}}{2}+i_{c} \\
i_{l}=\frac{i_{d c}}{3}-\frac{i_{s}}{2}+i_{c}
\end{gathered}
$$

where $i_{c}$ is called "circulating current". This current does not influence the AC nor the DC currents as it stays within the converter phases, but it has a significant second harmonic component that contributes to the losses.

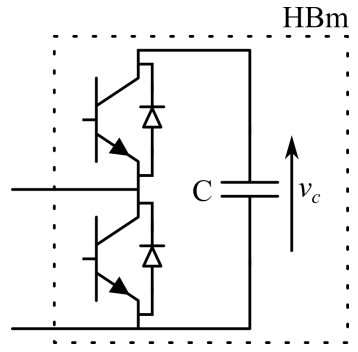

Fig. 2. Half-bridge module topology

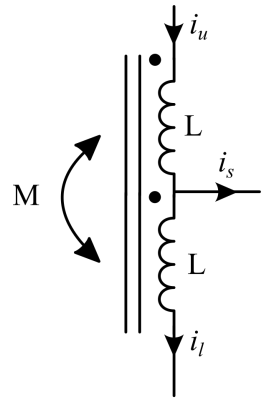

(a) (b)

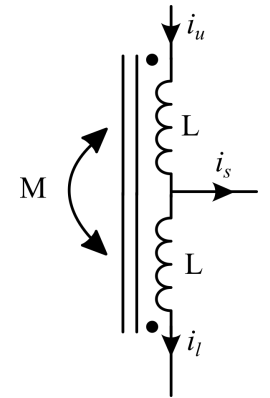

Fig. 3. Coupled arm inductors (a) $k_{c}>0$, (b) $k_{c}<0$

\section{B. Control of the MMC}

The control of an MMC with coupled arm inductors is similar to the one of a conventional MMC [3]. A cascaded control in the $d q$ reference frame is adopted here. The inner loop controls the d-and q-axis current while the outer loop controls the active and reactive power. The decoupling of the $\mathrm{d}$ - and q-axis takes into account the mutual arm inductance $M$. The PI controllers are tuned using the symmetrical optimum method, similarly to [13] but modified to account for the influence of $M$. The converter is synchronized with the grid using a Phase Locked Loop. The control scheme also includes Nearest Level Control (NLC) and Capacitor Voltage Balancing (CVB) algorithms [3]. But, no Circulating Current Suppression Controller (CCSC) has been implemented in order to underline the influence of the arm coupling on the circulating current.

\section{Coupled arm inductors}

There are two possibilities to magnetically couple the inductors as shown in Fig 3. Following the dot convention, if both currents enter the dotted terminals, the mutual inductance is positive. The coupling coefficient $k_{c}$ is defined as [14],

$$
k_{c}=\frac{M}{\sqrt{L L}}
$$

where $L$ is the arm inductance and $M$ is the mutual inductance between the two inductors in one phase. Theoretically, $-1<$ $k_{c}<1$. In a traditional MMC, the coupling coefficient is equal to zero. With the conventions for currents from Fig. 1, $k_{c}$ is positive in Fig. 3a and negative in Fig. 3b. This article deals with cases of positive and negative coupling coefficient $k_{c}$. 


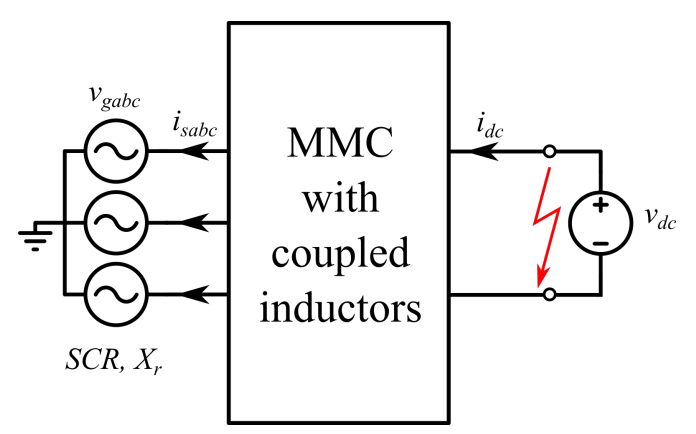

Fig. 4. MMC connection to the grid

\section{Capacitor and inductor design}

The module capacitance $C$ is calculated according to the desired maximum voltage ripple [15], [16],

$$
C=\frac{1.22 S}{3 \pi f v_{d c} V_{c} \Delta v_{c}}
$$

where $S$ is the nominal apparent power, $f$ is the grid frequency, $V_{c}$ is the average capacitor voltage and $\Delta v_{c}$ is the peak-to-peak fluctuation of the capacitor voltage in per unit.

The inductance value is determined according to the desired maximum circulating current amplitude. Adapted from [9] to include the arm coupling,

$$
L+M=\frac{1}{32 \pi^{2} f^{2} C V_{c}}\left(\frac{S}{3 I_{c}}+v_{d c}\right)
$$

where $I_{c}$ is the amplitude of the circulating current.

\section{RESULTS}

\section{A. Test case}

Simulations have been performed with Matlab/Simulink SimPowerSystems using a detailed MMC model with coupled arm inductors. The simulation parameters are summarized in Table I. To design the converter, the maximum peak-to-peak voltage ripple $\Delta v_{c}$ is taken equal to $0.6 \mathrm{p}$.u, and the maximum circulating current amplitude $I_{c}$ is set to 2 A corresponding to $10 \%$ of the AC grid current amplitude $I_{s}$. The simulation sequence is the following. During the first second of operation there is no power transfer. At $t=1 \mathrm{~s}$, the nominal active power is transferred from the DC grid to the AC grid. At $t=3 \mathrm{~s}$, a pole-to-pole short circuit fault of $300 \mathrm{~ms}$ duration occurs.

\section{B. Influence of the coupled inductors on the normal operation}

To demonstrate that there is no degradation of the performances in normal operation, simulations with zero, negative and positive coupling coefficient have been conducted. The active power and DC grid current are shown in Fig. 5. For $k_{c}=0$, the operation corresponds to the traditional MMC without arm coupling. The active power reaches its reference value thus showing the proper operation of the converter. During the transient, the DC current overshoot is equal to $23 \%$. For $k_{c}=-0.5$, the operation is satisfactory. Note that there is no DC current overshoot but that the DC current has
TABLE I

MMC PARAMETERS

\begin{tabular}{|c||c||c|}
\hline Parameter & Symbol & Value \\
\hline \hline AC grid SCR & $S C R$ & 3 \\
\hline AC grid X/R ratio & $X_{\text {ratio }}$ & 10 \\
\hline AC grid voltage & $v_{g}$ & $60 \mathrm{~V}$ \\
\hline AC grid frequency & $f$ & $50 \mathrm{~Hz}$ \\
\hline DC grid voltage & $v_{d c}$ & $150 \mathrm{~V}$ \\
\hline Apparent power & $S$ & $2000 \mathrm{VA}$ \\
\hline Switching frequency & $f_{s w}$ & $2000 \mathrm{~Hz}$ \\
\hline Average capacitor voltage & $V_{c}$ & $30 \mathrm{~V}$ \\
\hline Number of modules per arm & $N$ & 5 \\
\hline Arm inductor resistance & $R$ & $1 \Omega$ \\
\hline Modulation index & $m$ & 0.8 \\
\hline \hline Module capacitance & $C$ & $1960 \mu \mathrm{F}$ \\
\hline Arm inductance & $L$ & $10 \mathrm{mH}$ \\
\hline
\end{tabular}

larger ripples than without coupling. For $k_{c}=0.5$, the DC current overshoot is equal to $36 \%$. This is larger than the overshoot observed without arm coupling.

\section{Influence of the coupled inductors on the circulating cur- rent}

Remind that no Circulating Current Suppression Controller has been used. For steady state operation, the AC grid currents, the capacitor voltages and the circulating current are shown in Fig. 7. For the traditional MMC with $k_{c}=0$, the circulating current amplitude is $I_{c}=2 \mathrm{~A}$, in agreement with the design. For $k_{c}=-0.5$, the circulating current amplitude is increased to $7.5 \mathrm{~A}$. A theoretical value of $8.1 \mathrm{~A}$ is obtained from the Eq. (10). For $k_{c}=0.5$, the circulating current amplitude is reduced to $1.5 \mathrm{~A}$. A theoretical value of $1.22 \mathrm{~A}$ is obtained from the Eq. (10).

This behavior can be explained from Eq. (10). In Fig. 6, the circulating current amplitude is plotted as a function of $k_{c}$. For $k_{c}<-0.7$ the amplitude would be negative for the considered converter parameters (Table I), and therefore this value is the limit for the inductor design procedure. Above this limit, when $k_{c}$ increases, the circulating current amplitude decreases. A reduction of the circulating current amplitude reduces the arm currents harmonic distortion, and thus decreases switching and conduction losses of the switches.

Another way of explaining the observed behavior is to look the equivalent impedance $Z_{c, e q}$ viewed from the circulating current point of view,

$$
Z_{c, e q}=2 \sqrt{R^{2}+(2 \pi f(L+M))^{2}}
$$

An increase of the coupling coefficient results in an increase of $Z_{c, e q}$, and therefore in a diminution of the circulating current amplitude. Therefore it is desirable to have a positive coupling coefficient between the inductors. 

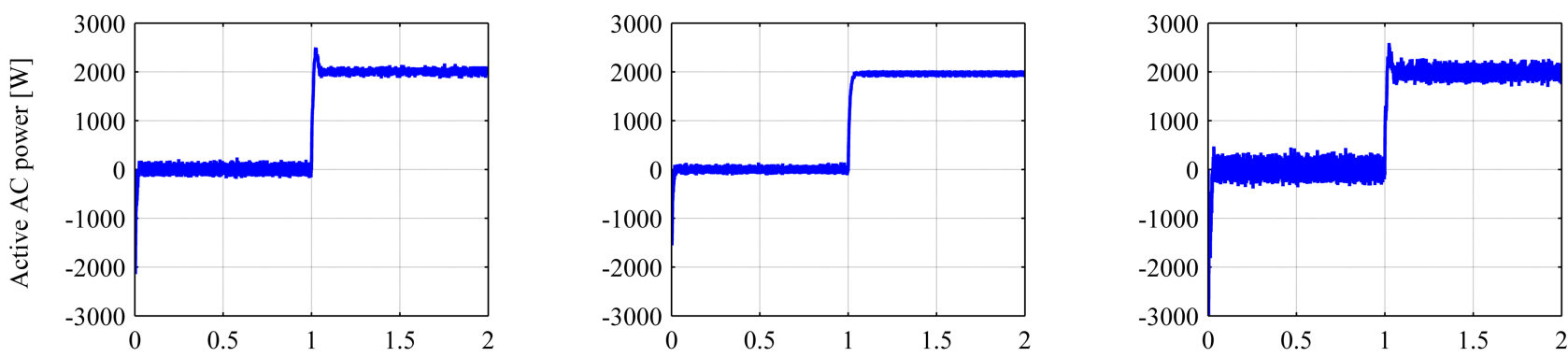

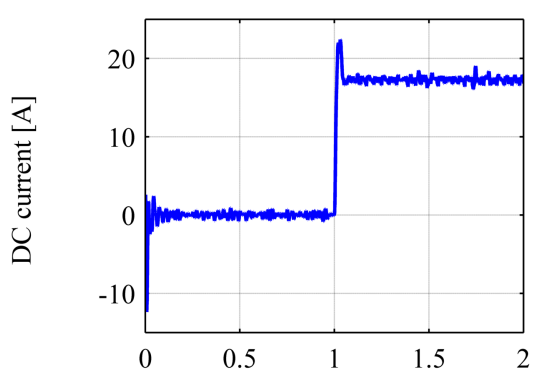

(a) Time $[\mathrm{s}]$

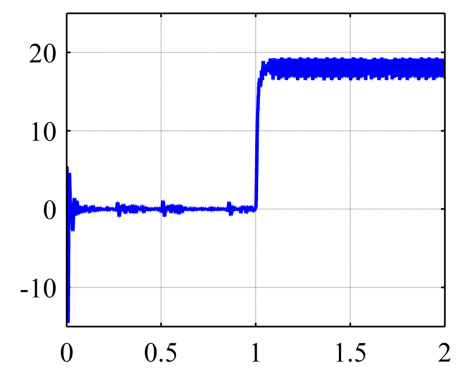

(b) Time $[\mathrm{s}]$

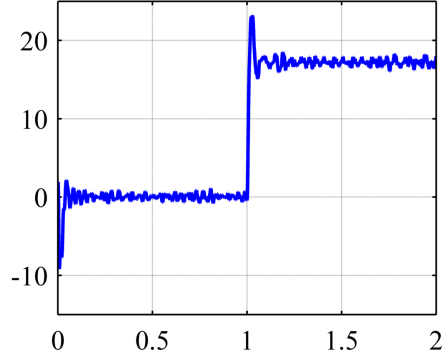

(c) Time $[\mathrm{s}]$

Fig. 5. Active power transfer and DC current for (a) $k_{c}=0$, (b) $k_{c}=-0.5$ and (c) $k_{c}=0.5$

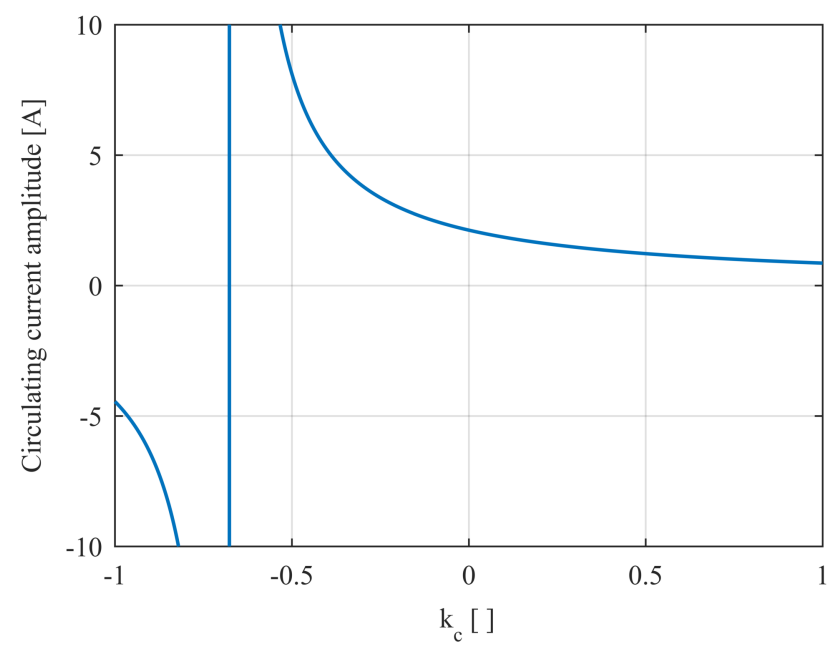

Fig. 6. Circulating current amplitude versus $k_{c}$, according to Eq. (10) for the parameters in Table I

\section{Influence of the coupled inductors on the capacitor voltage ripple}

For steady state operation, the AC grid currents, the capacitor voltages and the circulating current are shown in Fig. 7a. For $k_{c}=0$, the capacitor voltage ripple is equal to 0.5 p.u., thus respecting the design constraint. For $k_{c}=-0.5$, the capacitor voltage ripple is equal to 0.83 p.u. This is larger than the design constraint. For $k_{c}=0.5$, the capacitor voltage ripple is equal to 0.48 p.u..

The observed variation of the capacitor voltage ripple with the coupling coefficient proves that there is a direct link between the arm inductance and the capacitor voltage ripple. This seems in contradiction with Eq. (9). But the derivation of that equation was made assuming that "no harmonic current is circulating in the arms" [15]. In our simulation, no Circulating Current Suppression Controller has been used and therefore this hypothesis is not valid.

\section{E. Influence of the coupled inductors on the DC short-circuit current}

The AC grid currents, the DC grid current and the circulating current during the short circuit are shown in Fig. 8. For the traditional MMC with $k_{c}=0$, the DC short-circuit current is $i_{d c, s c}=-38.2 \mathrm{~A}$. For $k_{c}=-0.5$, it is reduced to $-26.9 \mathrm{~A}$, while for $k_{c}=0.5$ it reaches $-57 \mathrm{~A}$.

This behavior can be explained considering the equivalent impedance $Z_{e q}$ that consists of the grid impedance in series with the MMC [3], [17],

$$
\begin{gathered}
R_{e q}=\frac{V_{g L L}}{S} \frac{1}{S C R \sqrt{1+X_{\text {ratio }}^{2}}}+\frac{R}{2} \\
X_{e q}=\frac{V_{g L L}}{S} \frac{X_{\text {ratio }}}{S C R \sqrt{1+X_{\text {ratio }}^{2}}+2 \pi f\left(\frac{L-M}{2}\right)} \\
Z_{e q}=\sqrt{R_{e q}^{2}+X_{e q}^{2}}
\end{gathered}
$$

where $V_{g L L}$ is the amplitude of the line-to-line AC grid voltage, $S C R$ is the AC grid Short Circuit Ratio and $X_{\text {ratio }}$ is the AC grid $X / R$ ratio. From above expressions, it is clear that $Z_{e q}$ decreases when $k_{c}$ increases. So a negative coupling coefficient is desirable in to reduce the value of the DC shortcircuit current because the equivalent impedance seen from the DC grid is increased. 

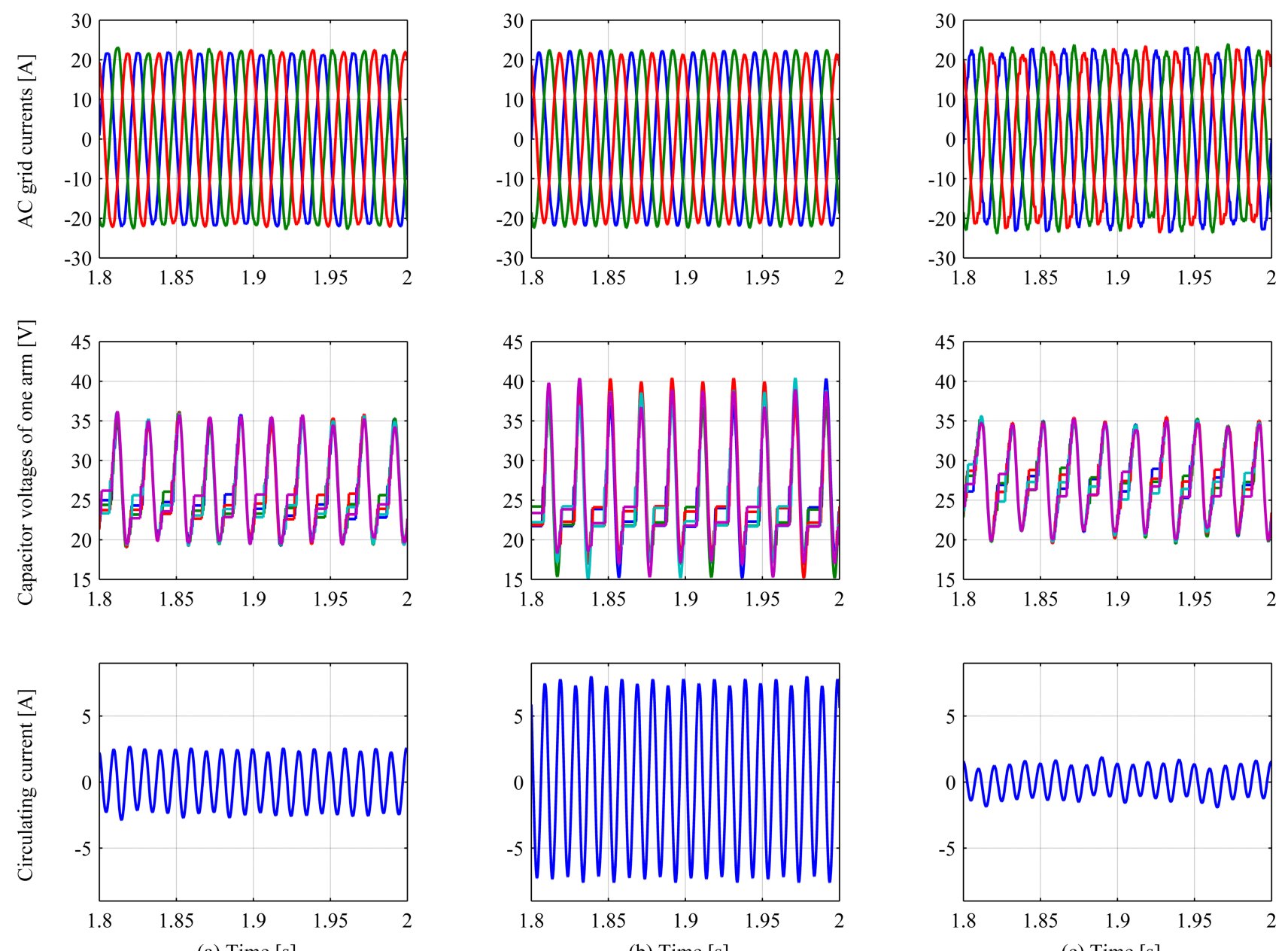

Fig. 7. AC currents, arm capacitor voltages and circulating current for (a) $k_{c}=0$, (b) $k_{c}=-0.5$ and (c) $k_{c}=0.5$

\section{F. Influence of the coupled inductors on switch losses}

Conduction and switching losses are calculated for both IGBTs and diodes [18], [19] in steady state operation. For $k_{c}=0$, the losses are estimated to be equal to $p_{\text {loss }}=222 \mathrm{~W}$. For $k_{c}=0.5$, the losses stay similar $(217 \mathrm{~W})$, whereas for $k_{c}=-0.5$ they increase to $264 \mathrm{~W}$. This shows that when $k_{c}$ decreases, the circulating current increases together with the losses.

\section{CONCLUSION}

This article summarizes the influence of arm inductor coupling of an MMC. We studied the behavior of the MMC with positive and negative coupling coefficients and compared them to the traditional MMC with non-coupled arm inductors. The following conclusions have been reached:

- With minor alterations a conventional control scheme can be used to regulate the power flow,

- A positive coupling coefficient decreases the amplitude of the circulating current and does not significantly affect the capacitor voltage ripple,
- A negative coupling coefficient augments the amplitude of the circulating current together with the capacitor voltage ripple,

- The switch losses are increased for negative coupling coefficient.

- During a DC short-circuit, a negative coupling coefficient reduces the value of the DC short-circuit current.

This study shows that the objectives of decreasing both DC short-circuit current and circulating current by using coupled arm inductors are contradictory. But, this could be solved with an adapted control strategy for circulating current suppression. Then an improved operation of an MMC can be obtained with only minor modifications.

\section{REFERENCES}

[1] A. Lesnicar, R. Marquardt, "An innovative modular multi-level converter topology for a wide power range," IEEE Power Tech Conference, Bologna, Italy, June 2003.

[2] N. Chaudhuri, B. Chaudhuri, R. Majumder, A. Yazdani, Multi-terminal direct-current Grids: modeling, qnalysis and control, Wiley, 2014.

[3] D. Jovčić, K. Ahmed, High voltage direct current transmission: converters, systems and DC grids, Wiley, 2015. 

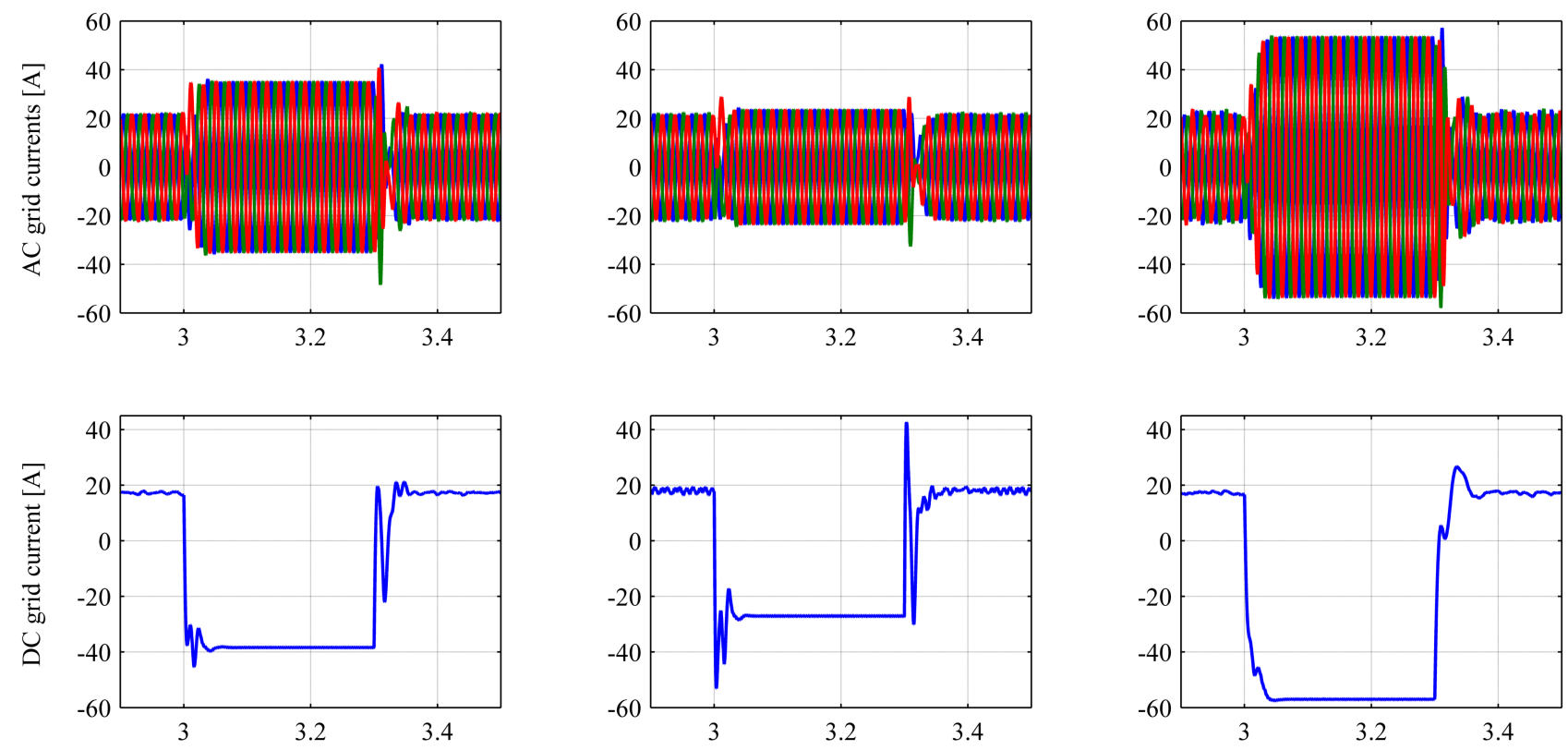

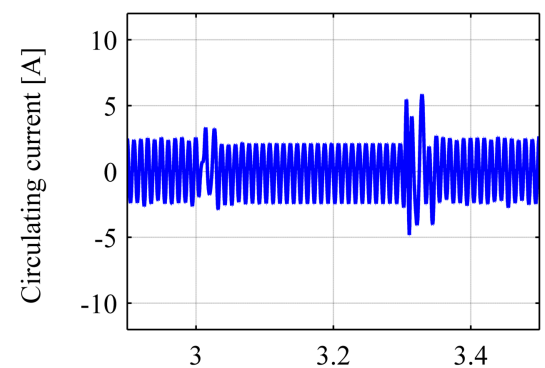

(a) Time $[s]$

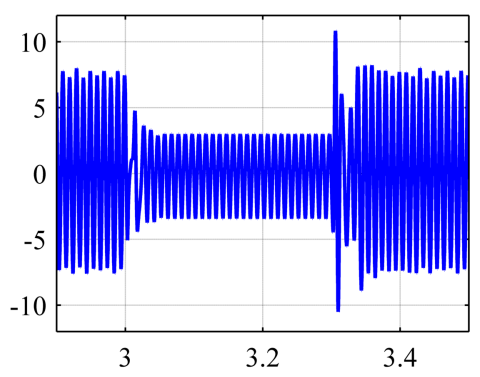

(b) Time $[\mathrm{s}]$

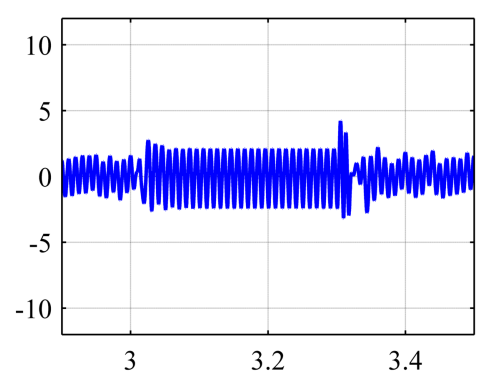

(c) Time $[\mathrm{s}]$

Fig. 8. AC grid currents, DC grid current and circulating current during a DC short-circuit for (a) $k_{c}=0$, (b) $k_{c}=-0.5$ and (c) $k_{c}=0.5$

[4] T. H. Nguyen, D.-C. Lee, "Protection of the MMCs of HVDC transmission systems against DC short-circuit faults," Journal of Power Electronics, 2017, vol. 17, no 1, p. 242-252.

[5] O. Cwikowski, A. Wood, A. Miller, M. Barnes, R. Shuttleworth, "Operating DC circuit breakers with MMC," IEEE Transactions on Power Delivery, 2017.

[6] A. Wasserrab, G. Balzer. "Determination of dc short-circuit currents of MMC-HVDC converters for dc circuit breaker dimensioning," 11th IET International Conference on AC and DC Power Transmission, Birmingham, UK, 2015, pp. 1-7.

[7] S. Wenig, M. Goertz, M. Suriyah, T. Leibfried, "Active DC fault management of a bipolar full-bridge MMC-HVDC scheme with metallic return," IEEE International Energy Conference (ENERGYCON), Leuven, Belgium, 2016, pp. 1-6.

[8] G. P. Adam, B. W. Williams, "Half- and full-bridge modular multilevel converter models for simulations of full-scale HVDC links and Multiterminal DC Grids," IEEE Journal of Emerging and Selected Topics in Power Electronics, vol. 2, no. 4, pp. 1089-1108, Dec. 2014.

[9] Q. Tu, Z. Xu, H. Huang, J. Zhang, "Parameter design principle of the arm inductor in modular multilevel converter based HVDC," International Conference on Power System Technology, Hangzhou, Zhejiang Province, China, 2010.

[10] X. Shi, Z. Wang, L. M. Tolbert, F. Wang, "Modular multilevel converters with integrated arm inductors for high quality current waveforms," IEEE ECCE Asia Downunder, pp. 636-642, Melbourne, Australia, 2013.

[11] J. Kucka, D. Karwatzki, L. Baruschka, A. Mertens, "Modular mul- tilevel converter with magnetically coupled branch inductors," IEEE Transactions on Power Electronics, vol. 32, no. 9, pp. 6767-6777, 2017.

[12] Y. Yuan, B. Zhu, "A control strategy based on of modular multilevel converters with coupled inductances," International Conference on Power System Technology, Chengdu, China, 2014, pp. 2056-2062.

[13] L. Quéval, H. Ohsaki, "Back-to-back converter design and control for synchronous generator-based wind turbines," International Conference on Renewable Energy Research and Applications (ICRERA 2012), Nagasaki, Japan, Nov. 2012.

[14] R.W. Erickson, D. Maksimović, Fundamentals of power electronics, Springer Science \& Business Media, 2007.

[15] M. M. C. Merlin, P. D. Judge, T. C. Green, P. D. Mitcheson, F. Moreno, K. Dyke, "Alternate arm converter operation of the modular multilevel converter,' IEEE Energy Conversion Congress and Exposition (ECCE), Pittsburgh, PA, USA, 2014, pp. 1924-1930.

[16] V. Najmi, Modeling, control and design considerations for modular multilevel converters, Master Thesis, VirginiaTech, Blacksburg, VA, USA, 2015.

[17] J. Freytes, S. Akkari, J. Dai, F. Gruson, P. Rault, X. Guillaud, "Smallsignal state-space modeling of an hvdc link with modular multilevel converters," IEEE 17th Workshop on Control and Modeling for Power Electronics (COMPEL), pp. 1-8, Trondheim, Norway June 2016.

[18] mathworks.fr, "Loss calculation in a threephase 3-level inverter", 2017. [Online]. Available: https://fr.mathworks.com/help/physmod/sps/examples/loss-calculationin-a-three-phase-3-level-inverter.html [Accessed 16- Nov - 2017]

[19] S. Munk-Nielsen, L. N. Tutelea, and U. Jaeger, "Simulation with ideal switch models combined with measured loss data provides a good 
estimate of power loss," IEEE Industry Applications Conference, vol.

5., pp. 2915-2922, 2000 